Paper: EJM-119 (56/07)

\title{
The Role of Insight Teams in Integrating Diverse Marketing Information Management Techniques
}

\author{
Craig S. Fleisher, Sheila Wright \& Helen T. Allard \\ Dr Craig S. Fleisher \\ Windsor Research Leadership Chair \& Professor of Management \\ Odette School of Business \\ University of Windsor \\ 401 Sunset Ave \\ Odette Building 508 \\ Windsor \\ Ontario N9B 3P4 \\ Canada \\ Phone: +1 5192533000 Ext: 3455 \\ E-Mail: fleisher@uwindsor.ca \\ Web: www.uwindsor.ca/business
}

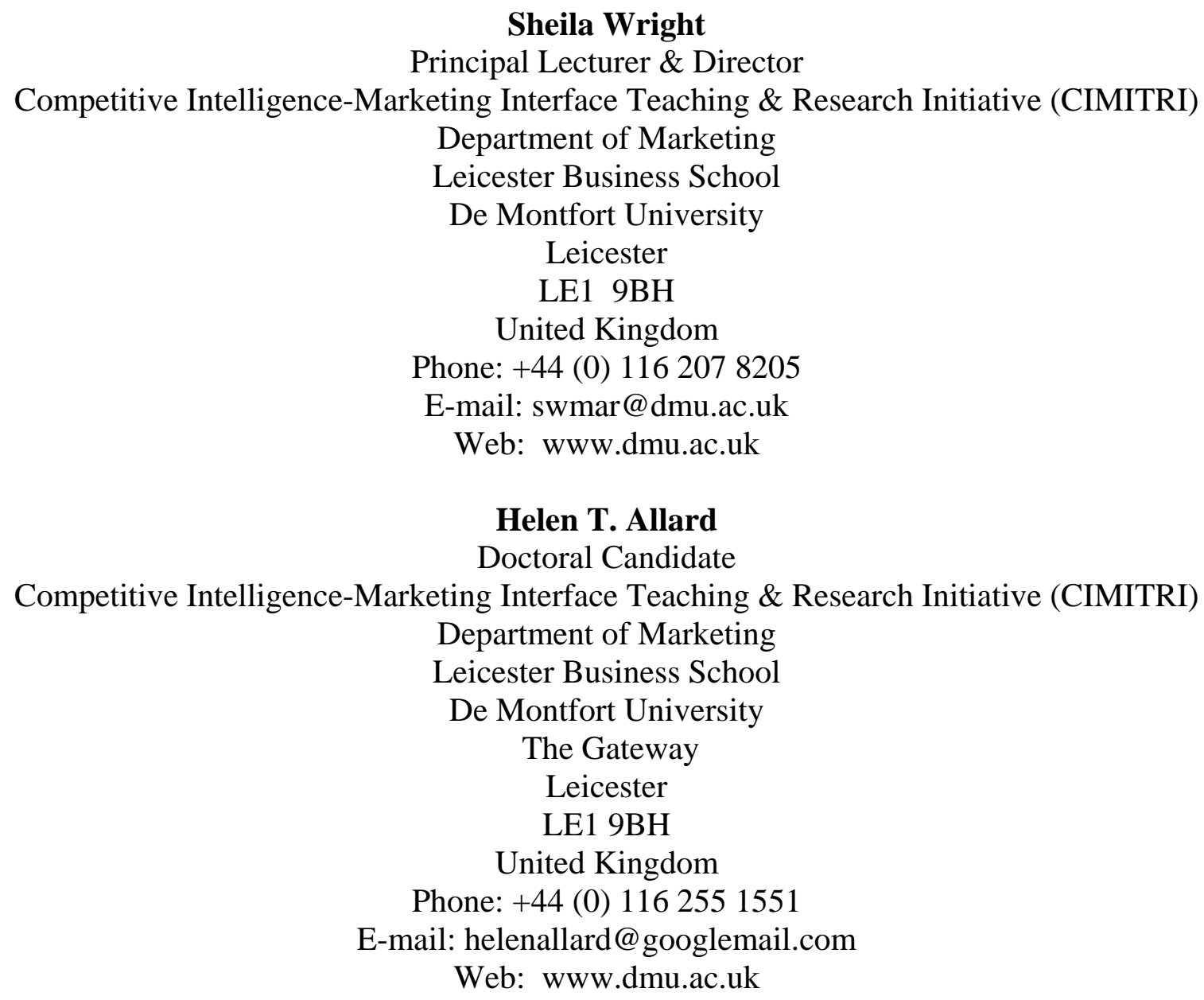

Sheila Wright

Principal Lecturer \& Director

Competitive Intelligence-Marketing Interface Teaching \& Research Initiative (CIMITRI)

Department of Marketing

Leicester Business School

De Montfort University

Leicester

LE1 9BH

United Kingdom

Phone: +44 (0) 1162078205

E-mail: swmar@dmu.ac.uk

Web: www.dmu.ac.uk

\section{Helen T. Allard}

Doctoral Candidate

Competitive Intelligence-Marketing Interface Teaching \& Research Initiative (CIMITRI)

Department of Marketing

Leicester Business School

De Montfort University

The Gateway

Leicester

LE1 9BH

United Kingdom

Phone: +44 (0) 1162551551

E-mail: helenallard@googlemail.com

Web: www.dmu.ac.uk 


\section{BIOGRAPHIES}

\section{Craig S. Fleisher}

Dr. Craig Fleisher holds the Windsor Research Leadership Chair and is Professor of Management (Strategy and Entrepreneurship) at the Odette School of Business, University of Windsor, Ontario, Canada. He is the immediate past-president and a Fellow of the global Society of Competitive Intelligence Professionals (SCIP), inaugural chair of the Competitive Intelligence Foundation (Washington, DC), and was founding Editor of the Journal of Competitive Intelligence and Management. An active researcher of topics in the business intelligence field, he has authored many articles and popular books including Business and Competitive Analysis (FT Press, 2007), Strategic and Competitive Analysis (Pearson, 2003), and Controversies in Competitive Intelligence (Praeger, 2003).

\section{Sheila Wright}

Sheila Wright is a Principal Lecturer at Leicester Business School, De Montfort University where she leads the Competitive Intelligence-Marketing Interface Teaching and Research Initiative (CIMITRI). She holds an MBA from the University of Warwick, has served on the board of SCIP and is Co-Editor for the Journal of Competitive Intelligence and Management (JCIM). She is a Fellow and Chartered member of CIM, and has authored or co-authored articles published in Marketing Intelligence \& Planning, European Journal of Marketing, R \& D Management, Journal of Marketing and Comportamento Organizacional e Gestao, Strategic Change and the Journal of Competitive Intelligence \& Management. Numerous CI related research projects have been undertaken under her supervision and she is a regular speaker and Workshop leader for CI and marketing related projects.

\section{Helen T Allard}

Helen Allard is a PhD student in Marketing at Leicester Business School, De Montfort University, UK. Helen was the Insights Manager at EAG. She worked with EAG's Board and Executive Committee to reposition and reinvigorate one of the employer association giants in her native country. Based on her efforts, she was rewarded with a permanent seat at the Executive Committee table - not somewhere you usually find the market research manager. Helen's qualifications are in Psychology and Law. She has a passion for interpreting and understanding the world and how it impacts on business. 


\begin{abstract}
Purpose - To address the viability of planning and executing the integration of four, often independent marketing information management techniques: competitive intelligence (CI), customer relationship management (CRM), data mining (DM) and market research (MR).

Design/methodology/approach - longitudinal, exploratory and descriptive case study, covering a three year period during a critical development phase of a medium-size, national employer association which sought to improve the quality of marketing-based insights to its strategic planning capability as well as improve economic outcomes.
\end{abstract}

Practical implications - The need to generate greater insight from popular marketing information management and planning techniques is routinely experienced by marketing and other executive decision makers. This article provides a multi-year roadmap of the successful execution of technique integration, including identifying barriers that arose as well as suggesting solutions for achieving progress.

Findings - It is possible to achieve profitable and capability enhancing integration of diverse marketing information management techniques. Successful integration and the use of a highly focused cross functional team generated better market strategies and bottom line benefits.

Originality/value - There are very few case studies published that demonstrate the successful evolution and integration of CI, CRM, DM and MR into the enterprise's strategy-making process. The unique element of this example was that it was achieved within the context of a medium-sized, national, not-for-profit employer association.

Keywords - Competitive Intelligence, Case Study, Cross-Functional Teams, Customer Relationship Management, Data Mining, Information Systems, Integration, Market Research.

Paper type Research paper/case study 


\section{Introduction}

The last few decades have seen a growth in organisational utilisation of competitive intelligence (CI), customer relationship management (CRM), data mining (DM) and market research (MR). The paper addresses the viability of planning and executing the integration of such independent marketing information management techniques. It is achieved through a longitudinal case study and a multi-year roadmap of a medium-size, national employer association which sought to improve the quality of marketing-based insights to its strategic planning capability as well as enhancing economic outcomes.

The literature is ripe with prescriptions as to the design and impact of cross-functional teams (CFTs), a focus of the integration effort described herein. Among others, Parker (2003) described CFTs as a group with a clear purpose representing a variety of functions or disciplines in the organization whose combined efforts are necessary for achieving the team's purpose. Sheard \& Kakabadse (2002) identified generic critical issues associated with the transformation of what they term "a loose group" into an effective team whilst more specifically, Holland et al (2000) and McDonough (2000), focused on the critical succesful factors for CFTs working on new product development. Research efforts have also looked at CFT decision making. Clark et al (2002) found that a key outcome in their study of a large multi-site organisation was the development of a knowledge directory system with organizational learning and individual learning components.

Context remains important in understanding integration. Denison et al (1996) looked at three domains of CFTs: organizational context, internal process, and outcome measures while more recently, Appelbaum \& Gonzalo (2007), developed a literature based conceptual model of twelve criteria which they considered important to achieving successful team dynamics and effectiveness. This was subsequently tested, using a case study approach, within a commercial firm where CFTs had been established for two years. They witnessed a distinct shift from a functional style of operation to a more matrix style. They also identified one of the important development issues facing the firm was how to maintain momentum and diffuse a cross-functional philosophy to lower levels of management.

It would seem that, in the right circumstances, not only is it possible to integrate various marketing information processes, but that successful CFTs can generate better market strategies and bottom line benefits. This case study offers a rare example where a significant degree of success was evident and quantifiable. Unlike the problems identified by Appelbaum \& Gonzalo (2007), the case reported here demonstrates that a high level CFT philosophy can successfully transfer to middle and lower levels of management, should the will to succeed be there.

\section{CI, CRM, DM and MR in Perspective}

There is a plethora of literature and research which highlights the potential competitive and economic value of each of these activities. CI is broadly defined for the purposes of this article to be the "strategic process of focusing the intelligence effort around critical success factors for organisational advantage" (Wright \& Pickton, 1998, p.76). More specifically, researchers and writers have demonstrated how CI can be critical in making sure that an enterprise's decision makers overcome their blind-spots (Gilad, 2004) and achieve early warning of opportunities or threatening developments (Fuld, 2006), more comprehensively account for the increasingly diverse and dynamic array of factors of competition (Day \& Schoemaker, 2006), to better understand and address specific competitors, customers and/or 
markets (Badr et al, 2004; Fleisher \& Bensoussan, 2004), and to improve the organization's general ability to learn about its customers and/or markets and to act upon that knowledge (Rothberg \& Erickson, 2005; Liebowitz, 2006). Studies have also been undertaken which look at aspects of CI information system integration (Noori \& Salimi, 2005), but not necessarily in marketing (Bhatt, 2000).

Similarly, there has been no shortage of articles extolling the beneficial aspects of excellent customer relationships. CRM is defined for the purposes of this article as "all about making adjustments to the way in which a bond is established between a company and some of their customers" (Gamble et al, 2006, p. 2). A number of authors have demonstrated the benefits of CRM, notably: developing CRM scales (Sin et al, 2005; Stone et al, 2002a), using CRM to generate better customer knowledge (Xu \& Walton, 2005), implementing CRM successfully (Bull, 2003; Lindgreen, 2004; Stone \& Van Bentum, 2005), integrating CRM with other business functions (Stone et al, 2002b), the engagement of CRM with relationship marketing (Mitussis et al, 2006) and the use of CRM within specific industry contexts such as banking, insurance or travel (Lindgreen \& Antioco, 2005; Stone et al, 2003).

DM is generally seen as a process of analyzing marketing-related data from different perspectives, summarizing this into useful information for planning and/or decision-making. Palace (1996) notes that DM is "primarily used today by companies with a strong consumer focus - retail, financial, communication, and marketing organizations”. DM allows companies to determine relationships among 'internal' factors such as price, product positioning or staff skills and 'external' factors, notably, economic indicators, competition and customer demographics. Done effectively, DM can help to empirically determine impacts on sales, customer satisfaction, and corporate profits (Nemati \& Barko, 2004). Numerous studies have been performed on the impact of DM such as its use for designing products (Agard \& Kusiak. 2004), integration with other marketing-oriented functions such as purchasing (Min \& Emam, 2004), and its use in particular industry contexts (Smith \& Dale, 2004; Watson et al, 2004).

MR may be the veteran among modern marketing information management techniques, having been in used and studied in great depth since the beginning of the $20^{\text {th }}$ century. The importance of market information, and particularly customer information, to marketing planning and management decisions is routinely accepted today (MRS, 2007). MR is defined here as "industry-targeted intelligence that is developed in real-time, examining aspects of competitive events taking place in the product or service market place in order to better understand the attractiveness of the market" (Skyrme 1989). Aaker (1998) notes that MR includes dimensions such as actual and potential market size, market growth, profitability, cost structure, distribution systems, market trends and developments, and key success factors. Specialist MR societies continue to recognize how important it is that managers understand how research and information integrates with the overall marketing process, as well as other marketing techniques (MRS, 2007), although the means for achieving this successfully remain much less certain.

\section{The Need for Cross-Functional Integration}

Questions about the integration of marketing information management techniques have long vexed practitioners and researchers (Stone, 2005; Wright \& Ashill, 1998). A number of studies have looked at the potential for integrating CRM and DM (Dillon \& Hope, 2004), CI and MR (Blenkhorn, 2003; Fleisher \& Bensoussan, 2004; Gilad, 2006), Business Intelligence (BI) and CRM (Stone et al 2002b; Gordon, 2002), and DM and MR within CRM (Elliott et al, 
2003). Despite these, managerial and scholarly concerns remain as to whether or not, marketing information system (MkIS) management techniques such as CI, CRM, DM and $\mathrm{MR}$, all designed for a specific purpose, are capable of compatible operation, and whether a variety of techniques like these could, or should, be successfully integrated in practice.

Marketing is nearly always likely to be unconventional in medium-sized enterprises and this often leads to firms of this size seeking alternative approaches to achieving results (Gilmore et $a l, 2001)$. In many SMEs, the personnel with strategy-focused skills exist in silos, disaggregated in a variety of roles across, for example, finance, marketing, IT, planning and/or sales, if they exist at all (Appelbaum \& Gonzalo, 2007). This failure to align efforts usually manifests itself within information systems that remain distinctly separate.

Subsequently, the work programs of such personnel are rarely aligned and the insights derived from their respective outputs are focussed too narrowly on relatively short-term operational and tactical issues. The consequence of this is two fold:

- Skills and projects addressing overlapping business questions cause duplication and consume greater resources than necessary, and

- The opportunity to uncover insights of strategic importance is lost. Instead, there is the increased potential for conflicting information and recommendations that create confusion, or hamper, rather than support, management decision making.

It was with the objective of avoiding this situation and attempting to optimise the return achieved on the costs associated with building such an integrated capability that an Insight Team began to evolve and the observations reported here were made.

\section{Research Methodology}

This case study is an exploration of a bounded system using multiple forms of data, rich in context (Yin, 1994; Creswell, 1998). According to Riege (2003), the case study approach permits holistic insights and analyses of previously unrecorded practitioners' experiences, which contain a wealth of information, frequently involving creative discovery. Cepeda \& Martin (2005) state three reasons why case study research is a viable approach. It allows a study of management in its actual context, and permits theoretical generalisations to be made. It provides material to answer complex "how" and "why" questions, thereby permitting a more accurate comprehension of the fundamental nature and degree of complexity inherent in the subject. It is also an appropriate way to explore areas in which previous studies are lacking, as was the case with this research.

The use of case studies to look at the integration of various marketing activities is somewhat common. Researchers have used this method to look at integrating marketing information systems (Wright and Ashill, 1998), using decision support systems to enhance marketing planning (Wilson, 2004), and mapping marketing information systems (Daniel et al, 2003). This research uses several approaches and as such, could be described as a longitudinal, explanatory, and descriptive case study. What is somewhat unique about the approach taken here, is the context of a medium-sized, national, not-for-profit organization. Real time observation and critical dissection of results was possible as one of the co-authors was not only employed by EAG, but was a key participant in the Insight Team. As such, our approach is a combination of project action research and case research, one which we would argue, delivers material, rich in depth and quality. 
The authors followed the process recommended by Wilson (2004) which is designed to minimize two practical methodological problems associated with employing this combination approach:

(1) rigorously analyzing action research data and

(2) taking steps to minimize the biases that potentially arise from the action researcher's dual role as participant and observer.

This included, among other things, the keeping and referencing of detailed, written diaries throughout the project, utilizing project management and planning techniques such as Project Evaluation Review Technique (PERT) diagrams which map out key steps of processes over designated time periods, and getting reliability checks by having other parties peripherally or even more centrally involved in the process to check the documentation for accuracy.

\section{EAG Background}

Over one hundred years old, Employers Association Group (EAG) is a national, memberbased mutual, a company limited by guarantee, owned by its members, employing around 300 staff and has annual operating revenue of $€ 18$ Million. It has no shareholders and does not pay dividends. The organisation's governance structure is multi-tiered using a series of elected councils. The CEO and executive management team are responsible for business operations and the Board is the principal decision-making body. The councils are widely consulted and their support is required before the Board can ratify strategic decisions.

In an effort to expand during the 1990s, EAG began to offer commercial business services such as industrial relations and employment law advice, international trade and heath and safety consulting services, apprenticeship schemes, an SME training centre and finally, publishing activities. A number of these failed to produce the expected returns, and the organisation found itself in an unsustainable position with reduced capital. These failures led its Board and executives to search for new ways to grow and strengthen the organization.

\section{Strategic Review}

During this phase, research revealed that most of EAG's members saw the greatest challenge to their future, came from the rapidly changing and increasingly complex business environment. Having identified this driver, EAG repositioned itself as a trusted, expert source of knowledge that could provide help. To deliver on this compelling, value proposition, executives identified three key areas which EAG needed to develop:

- Market \& CI capability - a wide spectrum of strategic analytic competencies focussed on analysis of the external business environment through secondary research at a global, national, industry and individual enterprise level.

- CRM capability - both software system development and analytical capabilities to facilitate internal data mining, previously the domain of software vendors

- MR capability - primary survey-based research skills, both qualitative and quantitative in nature.

Figure 1 below shows the inter-relationship of the disciplines which EAG ultimately brought together in an initiative named 'Insights', led by the Insight Team. 


\section{Figure 1 - The Integration of Activity which formed "Insights"}

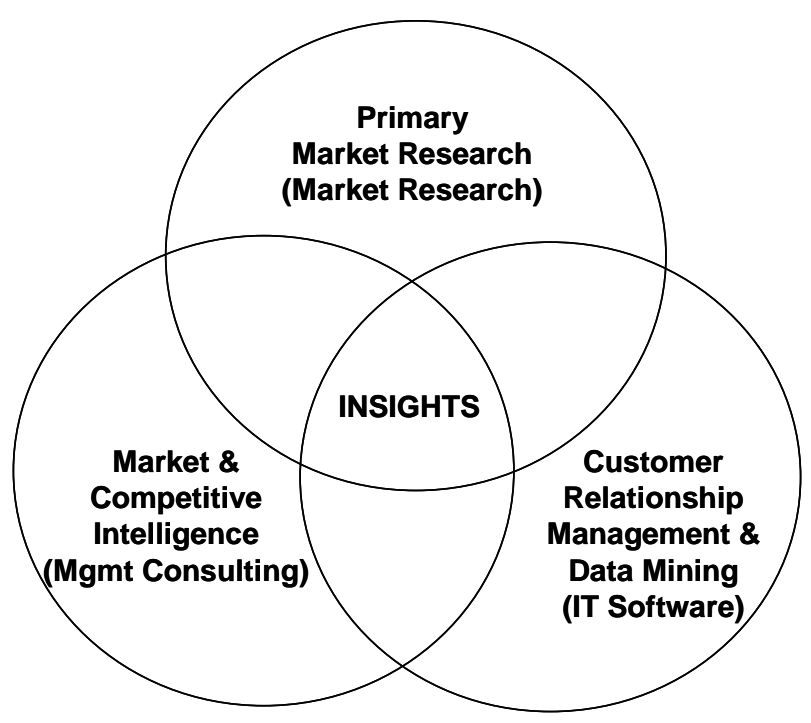

It was clear from the first phase of the strategic review that a substantial volume of ongoing and iterative MR and analysis was needed in order to successfully implement the strategy and new business model being developed.

An Insight Team Manager with a strong background in primary MR and strategy consulting was recruited with a direct report to the Executive General Manager, Strategy \& Marketing. The Insight Team Manager was not only responsible for all MR and analysis initiatives but had substantial budget control. This was significant as it immediately positioned MR as part of a strategic, rather than operational, competency at a very senior level in the organisation. The Insight Team was augmented over time with personnel in research and analytical roles from Marketing, IT, Finance and Sales. The team was responsible for all MR and market analysis tasks undertaken at this time.

\section{The Three-Year Plan}

EAG's internal data was poor due to aging and poorly integrated IT systems, a strongly siloed organisational structure, and a management culture of internal competition rather than collaboration. This had to be corrected and a three-year plan was devised.

Year 1: "Getting the house in order"

The objectives for Year 1 were:

- To understand the structure of EAG's markets and the needs of its members and customers;

- To consolidate the cost base and radically decrease expenditure;

- To deploy an enterprise-wide CRM system, integrate this with the existing finance system to facilitate market, product and financial analysis 
Year 2: "New beginnings"

Using the findings from Year 1, the objectives for Year 2 were:

- Restructure the product/service offering and adapt the pricing model

- Develop a list of accredited service/alliance partners to provide business that which was deemed to be outside EAG's core expertise

- Relaunch the brand

- Develop the CRM capability utilising the system initiated in Year 1

- Implement new channel strategies for core membership products

Year 3: "Leveraging for growth"

The objective in Year 3 was to continue driving growth in existing segments and product categories whilst identifying growth opportunities through NPD and acquisition. This required implementation of an enterprise-wide knowledge management system, a data warehouse suite of analytical tools including management dashboards to further facilitate both operational and strategic planning.

\section{Establishing EAG's Insight Team}

The development of EAG's Insight Team was iterative and evolved in response to the particular strategic decisions being addressed by the executive management team at various points during the implementation of the three-year Strategic Plan. It was tasked with conducting and/or commissioning the majority of the research and analysis that would underpin the successful implementation of the strategic plan.

The concept of an Insight Team was novel and came into being at a time when the organisation was undergoing substantial change. Many staff and external stakeholders, particularly state and regional councillors, were cynical about the vastly different strategic direction the organisation was taking. Consequently, it was important that the Insight Team quickly created its identity and galvanised support within the organisation. To achieve this, the team educated internal and external stakeholders as to its role and the value it could add to their business units and/or regions.

\section{Implementing the Plan}

Figure 2 provides a timeline which maps the major projects completed and the recruitment or redeployment of personnel across the organisation into a single, integrated team. Significant milestones achieved, or managed, over this period are also noted. 
Figure 2

Insight Team Implementation Timeline

\begin{tabular}{cc} 
Timeline & Projects \\
\cline { 2 - 2 } Yr 1 March & Fact Book \\
&
\end{tabular}

Yr 1 April

Yr 1 June

Yr 1 July

\begin{tabular}{c|c|}
\cline { 2 - 2 } Yr 1 Sept & Brand positioning research \\
\cline { 2 - 2 } Yr 1 Nov & $\begin{array}{c}\text { Market segmentation } \\
\text { research \& pricing model }\end{array}$ \\
\cline { 2 - 2 } &
\end{tabular}

Yr 1 Dec

\begin{tabular}{c|c|}
\cline { 2 - 2 } Yr 2 Feb & $\begin{array}{c}\text { Membership packages } \\
\text { product \& pricing } \\
\text { simulation project }\end{array}$ \\
\cline { 2 - 2 } Yr 2 April & $\begin{array}{c}\text { CRM data 'capture \& } \\
\text { cleanse' project }\end{array}$ \\
\cline { 2 - 2 } Yr 2 May & $\begin{array}{c}\text { Brand Health Monitor - } \\
\text { baseline \& wave 1 }\end{array}$ \\
\cline { 2 - 2 }
\end{tabular}

Yr 2 June

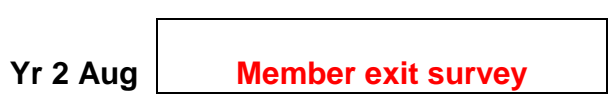

\begin{tabular}{c|c|}
\cline { 2 - 2 } Yr 2 Sept & $\begin{array}{c}\text { Food \& beverage industry } \\
\text { vertical strategy }\end{array}$ \\
\cline { 2 - 2 } Yr 2 Oct & $\begin{array}{c}\text { NPD Project 1 - Industrial } \\
\text { awards \& advice line }\end{array}$ \\
\cline { 2 - 2 } Yr 2 Nov & $\begin{array}{c}\text { Health industry vertical } \\
\text { strategy }\end{array}$ \\
\cline { 2 - 2 } Yr 2 Dec & $\begin{array}{c}\text { Brand Health Monitor - } \\
\text { wave } 2\end{array}$ \\
\cline { 2 - 2 } Yr 3 Jan & $\begin{array}{c}\text { Member Profiling Project } \\
\text { Yr } 3 \text { Feb }\end{array}$ \\
\cline { 2 - 2 } & $\begin{array}{c}\text { NPD Project 2 - Business } \\
\text { publishing products }\end{array}$ \\
Yr 3 Mar & $\begin{array}{c}\text { ICT industry vertical } \\
\text { strategy }\end{array}$ \\
\cline { 2 - 2 } Yr 3 Apr & $\begin{array}{c}\text { Member product usage and } \\
\text { P\&L project }\end{array}$ \\
\cline { 2 - 2 } Yr 3 May & $\begin{array}{c}\text { Brand Health Monitor - } \\
\text { wave } 3\end{array}$ \\
\cline { 2 - 2 } &
\end{tabular}

Yr 3 July
Insight Team Personnel

Milestones

\begin{tabular}{|c|}
\hline $\begin{array}{c}\text { Insight Team Manager } \\
\text { (new hire) }\end{array}$ \\
\hline
\end{tabular}

\begin{tabular}{|c|}
\hline Customer Database \\
Administrator \\
(from Finance) \\
Corporate Library - \\
Reference Librarians (2) \\
(from Finance) \\
\hline
\end{tabular}
Board approves three-year strategic plan
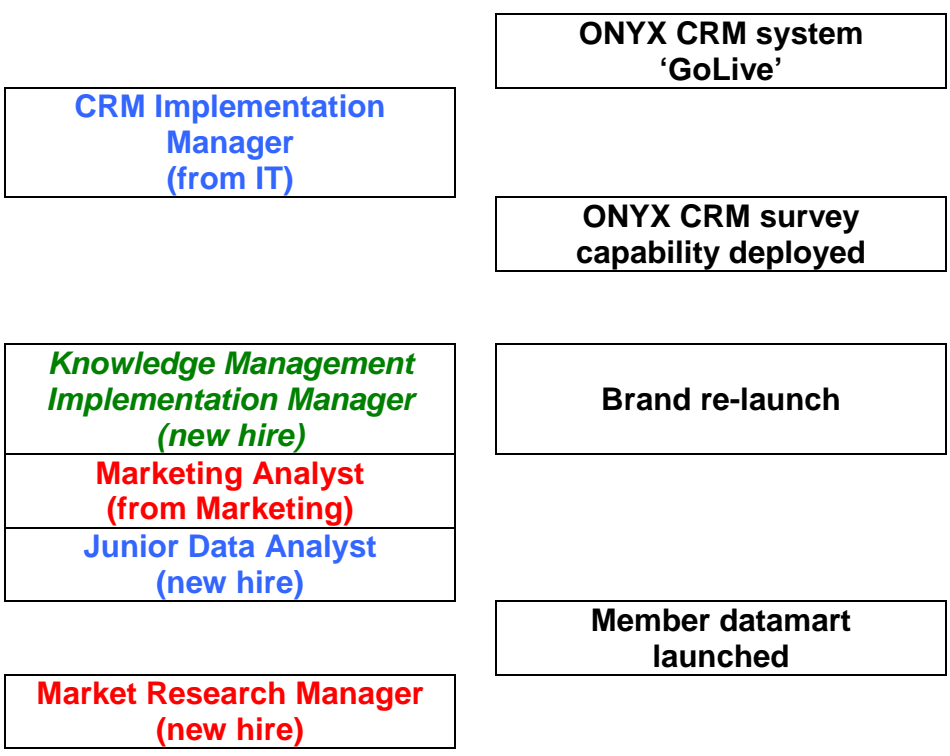

ONYX CRM survey capability deployed

Brand re-launch launched

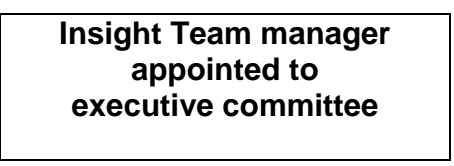

\begin{tabular}{|c|}
\hline Group Program Office \\
Manager \\
(from IT)
\end{tabular}

Legend - Market Research, CRM/ Marketing Analytics, Competitive Intelligence 


\section{Phase 1 - Market Research Capability}

A presentation of the market segmentation research was rolled out across the organisation. The research comprised a choice-based conjoint design from which a predictive segmentation model was developed. Nine market segments were identified within a customised business lifecycle model. The variables used in the predictive model included 26 different business services respondent firms had utilised in the prior 12 months as well as a revenue split. A range of positioning attributes were included and used alongside a suite of firm demographics, to better understand the character of each segment. Two main groups were identified: 1) firms in a consolidation/maintenance phase of the lifecycle and 2) firms in a growth/expansion phase. It became clear that the services each group required would be significantly different,

\section{Phase 2 - Customer Relationship Management Capability}

On completion of the market segmentation and positioning research, a new CRM system, Onyx, went live. This heralded a wave of discontent from many frontline staff who now had to comply with standardised procedures in their contacts with members and customers. The conversion of data from the old customer database into Onyx was the primary driver to integrate EAG's market research and CRM capabilities.

The next step used the survey tool in Onyx to assign member firms to particular market segments. This, combined with industry classification data and the role of key contacts within each member firm, was critical to the below-the-line marketing and sales strategies.

Consequently, the Insight Team was tasked with cleansing and capturing all the data required by business units, sales force and marketing teams to enable them to serve member firms.

An exit survey was also undertaken with firms which had not renewed their membership. The main reason identified was that the services they had sought were not adequately customised for their specific industry sector. This resulted in a significant change to EAG's approach to developing new business. The Insight Team was called upon to develop an Industry Vertical Strategy and, based on an analysis of both incumbent capability and a detailed analysis of the economic and growth prospects of various sectors, make recommendations as to which industry sectors should be targeted. It was this project that ultimately resulted in the integration of both the MR and CRM capabilities with that of the CI discipline. This cemented the Insight Team's position at the centre of the organisation's strategic thinking.

\section{Phase 3 - Market \& Competitive Intelligence Capability}

The corporate library was staffed by reference librarians with expertise in information, knowledge and/or library management. Some also held MBA qualifications. These staff worked closely with staff during the strategic review and conducted secondary research that underpinned a document known as the Fact Book. This documented the rationale behind the three-year plan. When the Insight Team was required to conduct industry analyses, the skills and experience developed during this phase proved valuable and obviated the need to outsource this task. This was the first project the Insight Team conducted that fully utilised all of the desired disciplines.

An example of the type of benefit that flowed from integrating personnel from each discipline into a single team was the development and use of standardised scales and range protocols 
such that analysis conducted using internal data or results obtained from MR could be directly compared with external data sources without substantial re-coding or manipulation. When the marketing team conducted a direct marketing campaign to a targeted group, they used the industry, firm size, turnover scales and standards implemented by the Insight Team. This type of consistency radically increased the productivity of analysts and enabled all personnel to spend more time on added-value analysis rather than data cleansing and manipulation.

\section{Outcome Measures and Impact of the Insight Team in EAG}

Industry dossiers for each of the sectors identified as strategic targets were developed by the Insight Team. These included analyses of:

- the industry value chain,

- market size and character,

- EAG's current service offering and penetration of each sector,

- details of key competitors offerings,

- other players in the sector with whom EAG may partner of form an alliance,

- existing member/ customer lists

- critical external issues impacting the sector

- information on the nuances or peculiarities of a given industry sector.

The dossiers were used to create training manuals for all market-facing and managerial staff which fostered collaboration between business units.

Integrating Insight Team personnel into a single team enabled joint KPI's (key performance indicators) to be developed which encouraged skill sharing and collaborative working across disciplines rather than staff working in operational silos.

This had measurable results in:

- Increased quality and timeliness of projects completed,

- Decreased spend on external suppliers and

- Increased productivity of the team overall.

Feedback from Insight Team members indicated that they found their roles challenging and rewarding. They also appreciated being exposed to, and working closely with, personnel from a variety of disciplines. Their individual skills set expanded rapidly, as did their ability to stay focussed on finding the answer to a strategic question. Over time, this ensured they spent very little time on work that was tangential to their main objective.

The relationships between the Insight Team and its internal clients, particularly Marketing, IT, Finance, Sales and the Executive Management team were enhanced by an ability to provide a one-stop-shop rapid response service. Conversely, when the volume of requests from across the organisation grew to a point where the team struggled to complete the task in the timeframes requested, a consolidated summary of the work effort could be prepared for Executive Management with recommendations as to resourcing priorities based on overall strategic imperatives. In this way, the organisation stayed tightly focussed on its strategic objectives and ensured the time and resources invested by the Insight Team were driven by the right priorities. 


\section{Specific Commercial and Competitive Successes}

One of the most impressive commercial successes flowing from the work of the Insight Team during this period was the creation and growth of EAG's Publishing Group. During the strategic review in Year 1, the development of a portfolio of information products was identified as an area from which new revenue streams could be built. The content for the products would be provided by EAG expert advisors and published through a range of web, multi-media and print channels. Prior to this time, EAG's Publishing Group had been a cost centre publishing just free-to-air and member newsletters and information alerts. Utilising the market segmentation research, the Publishing group identified two market gaps into which EAG could launch new web-based information products which leveraged EAG's existing knowledge and expertise. Whilst it was known that this would place EAG in direct competition with the two market leaders, the competitive intelligence and market information distilled by the Insight Team ensured they met the specific niche requirements of target segments, achieved good margins and took market share from their competitors.

These flagship products were a:

- $\quad$ subscription-based website, launched in Year 1 and targeted at human resources and industrial relations professionals and;

- $\quad$ subscription-based website, launched in Year 2 and targeted at health and safety managers professionals.

Analysis of member and customer data in Onyx further revealed opportunities to develop products to meet the more general information needs of SME owners and managers. For this group, analysis revealed that the preferred channel was CD-ROM and this led to the launch of three further products, namely, a Privacy Law Toolkit, an Employers Toolkit and an Occupational Health and Safety Toolkit.

The principal form of promotion for all products was highly targeted direct marketing campaigns to both current and non-members. Mailing lists of similar segmentation criteria were used, complemented by limited advertising in specific trade and professional publications. The Onyx CRM system enabled the Publishing Group to plan, track and analyse customer take up and use such competitive intelligence to hone subsequent waves of the campaign for optimal marketing ROI.

The revenues of the Publishing group increased from $€ 30,000$ in Year 1 to $€ 750.000$ in Year 3 with projected growth of the existing product portfolio of 38\% year on year. This forecast excluded additional future products already in the planning cycle and due for launch during Year 4.

Payback for the web products business cases was estimated at four and half years but was realised within the first two, following the launch of each of the flagship web products. Within four months of each CD-ROM being launched, the Publishing group achieved an ROI in excess of three hundred percent. Each of the products was designed to be updated and relaunched on an annual basis, producing substantial on-going revenue streams in successive financial years. 
Within three years, the combination of MR, CRM and CI skills inherent in the Insight Team facilitated the Publishing Group to become EAG's third largest profit centre after the law firm initiative and the Apprentice \& Trainee Centre.

\section{Lessons Learned}

At the outset of this paper we reported that managerial and scholarly concerns remain as to whether or not, marketing information management techniques such as CI, CRM, DM and MR, all designed for a specific purpose, could, or should, be successfully integrated in practice.

To answer this we have demonstrated how this was entirely viable within the context of a national, medium-sized, not-for-profit employer association. EAG managed to achieve the successful integration of CI, CRM, DM and MR, and this exercise took three years of deliberate action to produce a variety of positive performance results. Not every result, both good and less pleasant, was foreseen at the outset. Some of the market place outcomes went substantially beyond the organization's expectations. As with all firms seeking continual improvement, EAG recognises that as the task evolves and matures, they will have to seek additional ways to gain further advantage from integrating its marketing information management processes.

\section{Organisational Implications}

In retrospect, the process EAG used isn't readily replicable in other organizational contexts, but that is often the case when a firm finds a unique way of delivering success. As such, the generalizability of integrating diverse marketing information management techniques remains in question (Payne \& Frow, 2005; Stone, 2005). Market, organizational, political, social, and structural factors can greatly complicate the integration process. As can be seen from this case though, success requires, at a minimum, a well-planned integration strategy and structure (e.g., Insight Team), forward-thinking executives prepared to champion the cause, appropriate resource allocation such as time, skilled people, functional expertise and early positive results.

\section{Potential for Future Research}

We anticipate that other researchers will build on the study of integration and Insight Teams in differing contexts. We believe that additional longitudinal case study research of different forms of organisation, in different countries, in various industrial contexts can only enrich our knowledge of what factors are most critical in achieving full and profitable integration. Additionally, comparisons of companies within the same industry, some of which have successfully achieved integration and some that failed, may be conducted to see if there are any performance-related differences between these two groups. Lastly, there are excellent opportunities to further study integration processes, analyse tasks, and identify key steps and sequences that need to be carried out in order to achieve enhanced marketing insights.

\section{Conclusion}

After several difficult years, EAG needed to minimise costs, maximise profits and stay financially viable. The firm rose to the challenge of uncovering competitive advantage in a very difficult sector by creating an Insight Team. This enabled it to harness its MR, CRM, CI and DM resources, and translate those into products and services which were highly valued by 
its members and customers. This also differentiated EAG from its competitors and provided a basis for a sound economic future.

At the heart of the impetus for change was the realisation by EAG that it had not been serving its customers effectively. By changing its business model with the future in mind, the firm was able to better understand its markets, make more accurate predictions of customer needs and devise innovative ways of positioning its products and services. Behind this was the absolute belief, within both the executive management and the Insight Team that sustainable competitive advantage would come from information integration rather than information isolation.

The integrative capability developed at EAG is indicative of the types of marketing and management skills which firms will require in the future if they are to compete successfully in the knowledge economy.

\section{References}

Aaker, D.A. (1998). Strategic Market Management. New York: Wiley.

Agard, B. and Kusiak, A. (2004). "Data-mining-based Methodology for the Design of Product Families,” International Journal of Production Research, 42(15), pp. 2955-2969.

Appelbaum, S.H. and Gonzalo, F. (2007). "Effectiveness and Dynamics of Cross-Functional Teams: A Case Study of Northerntranspo Ltd.,” Journal of American Academy of Business, Cambridge, 10(2), pp. 36-44.

Badr, A., Wright, S., Pickton, D.W. \& Wallace, E. (2004). The Role of Competitive Intelligence in Implementing Marketing Strategy. Academy of Marketing Conference, Gloucester.

Blenkhorn, D. (2003). "What is the Best Form of Relationship Between Competitive Intelligence and Marketing?” pp. 281-294 in Fleisher \& Blenkhorn [eds.], Controversies in Competitive Intelligence: The Enduring Issues, Praeger, Westport, CT.

Bhatt, G.D. (2000). "An Empirical Examination of the Effects of Information Systems Integration on Business Process Improvement,” International Journal of Operations \& Production Management, 20(11), pp. 1331-1359.

Bull, C. (2003). “Strategic Issues in Customer Relationship Management (CRM) Implementation,” Business Process Management Journal, 9(5), pp. 592-602.

Cepeda, G. and Martin, D. (2005) A Review of Case Studies Publishing in Management Decision 2003-2004: Guides and Criteria for Achieving Quality in Qualitative Research, Management Decision, 43(6): pp. 851-876.

Clark, M.A., Amundson, S.D. and Cardy, R.L. (2002), "Cross-functional team decisionmaking and learning outcomes: a qualitative illustration", Journal of Business and Management, 8(3), pp. 217-236. 
Creswell, J.W. (1998) Qualitative Inquiry and Research Design: Choosing Among Five Traditions. London: Sage.

Daniel, E., Wilson, H. and McDonald, M. (2003). “Towards a Map of Marketing Information Systems: An Inductive Study,” European Journal of Marketing, 37(5/6), pp. 821-847.

Day, G.S. and Schoemaker, P.J.H. (2006). Peripheral Vision: Detecting the Signals that will Make or Break Your Company. Harvard Business School Press, Boston.

Denison, D.R., Hart S.L. and Kahn, J.A. (1996), "From Chimneys to Cross-Functional Teams: Developing and Validating a Diagnostic Model", The Academy of Management Journal, 39(4), pp. 1005-1023

Dillon, H. and Hope, B. (2004). "Translating Advances in Data Mining to Operations: The Art of Data Mining in Retailing,” pp. 263-278 in Nemati and Dale [Eds.]., Organizational Data Mining: Leveraging Enterprise Data Resources for Optimal Performance. Idea Group Publishing, London.

Elliott, K., Scionti, R, and Page, M. (2003). "Two Rivers - The Confluence of Data Mining and Market Research for Smarter CRM” available at: ftp://ftp.spss.com/pub/web/wp/2rivers.pdf

Fleisher, C.S. and Bensoussan, B. (2004). Strategic and Competitive Analysis: Methods and Techniques for Analysing Business Competition. Prentice Hall, London.

Fuld, L. (2006). The Secret Language of Competitive Intelligence: How to See Through and Stay Ahead of Business Disruptions, Distortions, Rumors, and Smoke Screens. AMACOM, New York.

Gamble, P.R., Stone, M., Woodcock, N. and Foss, B. (2006). “Up Close and Personal: Customer Relationship Marketing @Work,” $3^{\text {rd }}$ edition, Kogan Page, London.

Gilad, B. (2006). “Strategic Early Warning Revisited,” Competitive Intelligence Magazine, 9(2), March-April, pp. 17.

Gilad, B. (2004). Early Warning: Using Competitive Intelligence to Anticipate Market Shifts, Control Risk, and Create Powerful Strategies. AMACOM, New York.

Gilmore, A., Carson, D. and Grant, K. (2001). “SME Marketing in Practice,” Marketing Intelligence and Planning, 19(1), pp. 6-11.

Gordon, I.H. (2002). Competitor Targeting: Winning the Battle for Market and Customer Share. John Wiley \& Sons, Inc., Etobicoke, Ontario.

Holland S, Gaston K and Gomes J. (2000). "Critical success factors for cross-functional teamwork in new product development ", International Journal of Management Reviews 2(3), pp. 231-259

Liebowitz, J. (2006). Strategic Intelligence: Business Intelligence, Competitive Intelligence, and Knowledge Management. Auerbach Publications, Boca Raton, Florida. 
Lindgreen, A. and Antioco, M. (2005). "Customer Relationship Management: The Case of a European Bank,” Marketing Intelligence and Planning, 23(2), pp. 136-154.

Lindgreen, A. (2004). "The Design, Implementation and Monitoring of a CRM Programme: A Case Study,” Marketing Intelligence and Planning, 22(2), pp. 160-186.

McDonough, E.F. (2000), "Investigation of factors contributing to the success of crossfunctional teams", Journal of Product Innovation Management, 17(3), pp. 221-235

Min, H. and Emam, A. (2004). “A Data-mining Approach to Formulating a Successful Purchasing Strategy,” pp. 109-124 in Nemati and Dale [Eds.]., Organizational Data Mining: Leveraging Enterprise Data Resources for Optimal Performance. Idea Group Publishing, London.

Mitussis, D., O’Malley, L. and Patterson, M. (2006). "Mapping the Re-engagement of CRM with Relationship Marketing,” European Journal of Marketing, 40(5/6), pp. 572-589.

MRS-Market Research Society, (2007) “Qualifications for market researchers” found at: http://www.mrs.org.uk/qualifications/index.htm

Nemati, H.R. and Barko, C.D. (2004). Organizational Data Mining: Leveraging Enterprise Data Resources for Optimal Performance. Idea Group Publishing, London.

Noori, B. and Salimi, M.H. (2005). “A Decision-support System for Business-to-Business Marketing,” Journal of Business and Industrial Marketing, 20(4/5), pp. 226-236.

Palace, B. (1996). “Data mining,” Technical note prepared for Management 274A course offered at Anderson Graduate School of Management, University of California Los Angeles (UCLA) found at: http://www.anderson.ucla.edu/faculty/jason.frand/teacher/technologies/palace/index.ht $\underline{\mathrm{m}}$

Parker, G.M. (2003). Cross Cross-Functional Teams: Working With Allies, Enemies, And Other Strangers. Jossey-Bass: San Francisco

Payne, A. and Frow, P. (2005). “A Strategic Framework for Customer Relationship Management,” Journal of Marketing, 69(4), pp. 161-176.

Riege, A.M. (2003) Validity and Reliability Tests in Case Study Research: A Literature Review with "Hands-on” Applications for each Research Phase, Qualitative Market Research: An International Journal, 6(2): 75-86.

Rothberg, H. and Erickson, G.S. (2005). From Knowledge to Intelligence: Creating Competitive Advantage in the Next Economy. Elsevier Butterworth-Heinemann, Amsterdam.

Sheard, A.G. and Kakabadse, A.P. (2002), "From loose groups to effective teams: The nine key factors of the team landscape", Journal of Management Development, 21(2), pp. 133-151. 
Sin, L.Y.M., Tse, A.C.B. and Yim, F.H.K. (2005). "CRM: Conceptualization and Scale Development,” European Journal of Marketing, 39(11/12), pp. 1264-1290.

Skyrme, D.J. (1989). "The Planning and Marketing of the Market Intelligence Function,” Marketing Intelligence and Planning, 7(1/2), pp. 5-10.

Smith, K. and Dale, M. (2004). “A Porter framework for Understanding the Strategic Potential of Data Mining for the Australian Banking Industry,” pp. 25-45 in Nemati and Dale [Eds.], Organizational Data Mining: Leveraging Enterprise Data Resources for Optimal Performance. Idea Group Publishing, London.

Stone, M. (2005). “Integration - Why Bother?” Journal of Direct, Data and Digital Marketing Practice, 7(2), pp. 110-11.

Stone, M. and Van Bentum, R. (2005). "Customer relationship management and the impact of corporate culture,” Journal of Database Marketing and Customer Management Strategy, 13(1), pp. 28-54.

Stone, M., Foss, B. and Pula, E. (2003). "Customer Data Management in Practice - An Insurance Case Study,” Journal of Database Marketing, 10(4), pp. 327-341.

Stone, M., Woodcock N. and Machtynger, L. (2002a). Customer Relationship Marketing, 2nd edition, Kogan Page, London.

Stone, M., Dobbs, T. and Abbott, J. (2002b). "UK Data Warehousing and Business Intelligence Implementation,” Qualitative Market Research: An International Journal, 5(4), pp. 235-238.

Watson, H., Wixom, B. and Goodhue, D. (2004). "Data Warehousing: The 3M Experience," pp. 217-229 in Nemati and Dale [Eds.]., Organizational Data Mining: Leveraging Enterprise Data Resources for Optimal Performance. Idea Group Publishing, London.

Wilson H.N. (2004). "Towards rigour in action research: a case study in marketing planning," European Journal of Marketing, 38(3/4) pp. 378-400.

Wright, M. and Ashill, N. (1998). “A Contingency Model of Marketing Information,” European Journal of Marketing, 32 (1/2), pp. 125-144.

Wright, S. and Pickton, D.W. (1998). "Improved Competitive Strategy Through Value-added Competitive Intelligence," Proceedings of the 3rd Annual Society of Competitive Intelligence Professionals European Conference, Berlin, November, pp. 73-83.

Xu, M. and Walton, J. (2005). "Gaining Customer Knowledge through Analytical CRM," Industrial Management \& Data Systems, 105(7), pp. 955-971.

Yin, R.K. (1994) Case Study Research, Design and Methods, 2/E, London: Sage Publications. 